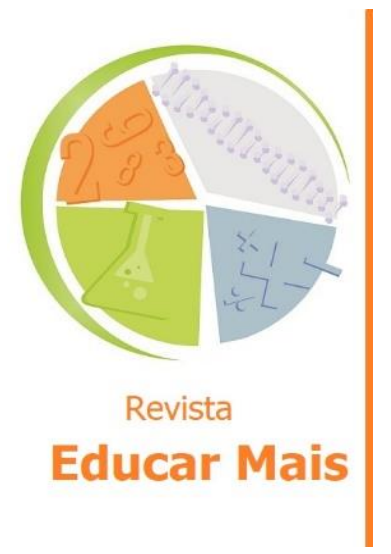

\section{Processos formativos mediados por tecnologias emergentes no estado de Rondônia em tempos de pandemia: o que dizem os professores?}

\author{
Formative processes mediated by emerging technologies in the state of \\ Rondônia at pandemic times; what do the teachers say?
}

\begin{abstract}
Procesos de formación mediados por tecnologías emergentes en el departamento de Rondônia en tiempos de pandemia: ¿qué dicen los profesores?
\end{abstract}

Rafael Fonseca de Castro ${ }^{1}$; Epifânia Barbosa da Silva²

\title{
RESUMO
}

Esta pesquisa investigou, a partir das percepções dos (denominados) professores articuladores de um processo de formação continuada realizado em Rondônia, via Ensino Remoto Emergencial, limites e possibilidades que permearam o uso de tecnologias nesse processo. Adotou-se teoricamente o conceito vygotskiano de mediação e a perspectiva de Tecnologias Emergentes (TE) para discutir a problemática. Os dados, provenientes de um questionário online e de observação participante, foram analisados à luz da análise textual discursiva e produziram os seguintes achados: i. em uma perspectiva vygotskiana, as tecnologias utilizadas atuaram na condição de ferramentas e de signos na atividade mediadora formação remota; ii. as aprendizagens mais relevantes, segundo os professores, foram as relativas ao uso das TE durante as formações, mais mencionadas até do que os conteúdos trabalhados; iii. as principais dificuldades relatadas foram a conexão de internet ruim nos municípios e a falta de conhecimento sobre o uso das tecnologias pelos professores; iv. os docentes se mostraram conscientes da importância do domínio de tecnologias na condição de educadores e otimistas com relação ao seu uso pedagógico em um cenário pós-pandemia.

Palavras-chave: Formação de professores; Ensino Remoto Emergencial; Mediação; Tecnologias Emergentes; Pandemia de COVID-19.

\begin{abstract}
This research investigated, from the perceptions of (so-called) "articulating teachers" a continuing education process carried out in Rondônia, through Emergency Remote Teaching, limits and possibilities that permeated the technologies uses in this process. The Vygotskian concept of mediation and the Emerging Technologies (ET) perspective were theoretically adopted to discuss the issue. The data, from an online questionnaire and from participant observation, were analyzed in the light of discursive textual analysis and produced the following findings: $i$. in a Vygotskian perspective, the technologies used acted as tools and as signs in the remote education mediation activity; ii. the most relevant learnings, according to the teachers, were those related to the ET uses during the formative process, more mentioned even more than the contents worked; iii. the main difficulties reported were the poor internet connection in the municipalities and the lack of knowledge about the use of technologies by the teachers; iv. teachers were aware of the importance of mastering technologies as educators and optimists regarding their pedagogical use in a post-pandemic scenario.
\end{abstract}

Keywords; Teacher training; Emergency Remote Teaching; Mediation; Emerging Technologies; COVID-19 pandemic.

${ }^{1}$ Doutor em Educação. Professor do Departamento de Ciências da Educação - Campus Porto Velho. Docente Permanente do Programa de Pós-Graduação em Educação (PPGE) e do Programa de Pós-Graduação em Educação Escolar (PPGEProf). Líder do Grupo de Pesquisa HISTCULT - Educação, Psicologia Educacional e Processos Formativos. Universidade Federal de Rondônia (UNIR). Porto Velho/RO - Brasil.

2 Mestranda em Educação pelo Programa de Pós-Graduação em Educação (PPGE), Universidade Federal de Rondônia (UNIR). Supervisora Escolar da Secretaria de Educação de Rondônia (SEDUC/RO). Especialista em Assuntos Educacionais da Secretaria Municipal de Educação de Porto Velho (SEMED). Porto Velho/RO - Brasil. 


\section{RESUMEN}

Esta investigación buscaba, a partir de las percepciones de (los llamados) profesores articuladores, un proceso de educación continua realizado en Rondônia, a través de Educación Remota de Emergencia, límites y posibilidades que permearon el uso de tecnologías en este proceso. El concepto vygotskiano de mediación y la perspectiva de Tecnologías Emergentes (TE) se adoptaron teóricamente para discutir el tema. Los datos, recolectados a partir de un cuestionario online y de observación participante, fueron analizados a la luz del análisis textual discursivo y arrojaron los siguientes hallazgos: i. en una perspectiva vygotskiana, las tecnologías utilizadas actuaron como herramientas y como signos en la actividad mediadora de formación remota; ii. los aprendizajes más relevantes, según los docentes, fueron los relacionados con el uso de TE durante la formación, más mencionados que los contenidos trabajados; iii. las principales dificultades reportadas fueron la mala conexión a internet en los municipios y el desconocimiento sobre el uso de tecnologías por parte de los docentes; iv. los profesores eran conscientes de la importancia de dominar las tecnologías como educadores y optimistas con respecto a su uso pedagógico en un escenario de después de la pandemia.

Palabras clave: Formación de profesores; Educación remota; Mediación; Tecnologías Emergentes; Pandemia de COVID-19.

\section{INTRODUÇÃO}

Uma das marcas das duas primeiras décadas do século XXI é o avanço das tecnologias móveis no diaa-dia da sociedade. Cotidianos individuais e coletivos foram direcionados a uma nova realidade comunicacional. Relações pessoais e laborais também. Mesmo antes da emergência sanitária global decorrente do novo corona vírus (SARS-CoV-2), conhecido como COVID-19, o uso de smartphones já era uma realidade cultural. Muito mais do que um telefone, esse artefato cultural passou a ser uma extensão de braços e mãos, em constante e sinérgica conexão com o cérebro humano desses tempos.

Mas o ano de 2020 está marcado historicamente pela pandemia de COVID-19, anunciada no mês de março pela Organização Mundial de Saúde (OMS). Medidas para conter o avanço da pandemia foram anunciadas por governos e corporações, entre elas, o isolamento social e demais restrições que afetaram profundamente o cotidiano das pessoas e setores das sociedades civis organizadas. Uma das áreas imediatamente atingida foi a Educação. Como enfatizam Guizo, Marcello e Müller (2020), creches, pré-escolas, escolas e universidades suspenderam atividades presenciais; parte da indústria e do comércio, de restaurantes e de serviços em geral foi igualmente fechada. O delivery, o takeaway, o home office e o homeschooling foram imediatamente instalados ou intensificados (pelo menos, para as classes média e alta) como formas de manter as famílias em casa. As tecnologias móveis, nesse contexto, assumem papel ainda mais preponderante, pois contribuem com a manutenção de situações comunicacionais em tempos de isolamento social físico.

No Brasil, aulas presenciais e programas de formação de professores em espaços físicos foram suspensos e atividades realizadas com o uso da internet foram largamente adotadas pelas escolas diante da situação de excepcionalidade imposta pela pandemia. Alternativas precisaram ser pensadas e executadas, mesmo que de forma aligeirada e pouco dialogada entre os envolvidos. Secretarias municipais e estaduais também precisaram se readequar no intuito de manter atividades previamente estabelecidas.

Respeitando e seguindo orientações da OMS e decretos de estados e municípios, e levando em consideração os recentes avanços nas telecomunicações e na microinformática, o denominado Ensino 
Remoto Emergencial (ERE) foi adotado por instituições públicas e privadas globalmente, sendo também utilizado no Brasil e no estado de Rondônia. O presente artigo, diante desse contexto, apresenta o resultado de uma pesquisa qualitativa sobre um programa de formação de professores realizado no estado de Rondônia que precisou ser adaptado para essa modalidade remota.

Trata-se do programa de formação de professores com foco na implantação do Referencial Curricular do estado de Rondônia (RCRO), que contou com a participação de uma equipe regional composta por 340 professores formadores/multiplicadores, sendo: 52 articuladores locais (os sujeitos da nossa pesquisa), responsáveis por coordenar a formação dos professores nos municípios e formar as equipes pedagógicas das escolas municipais sobre o Projeto Político Pedagógico (PPP) a partir do RCRO; 88 formadores para atuarem com a etapa da Educação Infantil (EI) e 200 formadores para atuarem com os componentes curriculares dos Anos Iniciais (AI) do Ensino Fundamental (EF). Esse processo formativo, complexo e de alto grau de capilaridade, contemplou, aproximadamente, 8500 professores, o que só foi possível pelo o uso de Tecnologias Emergentes (TE), com protagonismo do uso das tecnologias móveis pelos professores.

A pesquisa foi realizada com os 52 professores articuladores, que responderam a um questionário disponibilizado online no mês de setembro. As questões versavam sobre aprendizagens decorrentes da experiência formativa em formato remoto, sobre possibilidades de Trabalho Colaborativo entre seus participantes e sobre o uso das tecnologias ao longo das formações. Neste recorte da referida pesquisa, discorremos sobre limites, dificuldades e possibilidades propiciados pela utilização das TE ao longo do processo formativo, adotando como referencial o conceito vygotskiano de mediação (VYGOTSKI, 1931/1995; VYGOTSKY, 1934/1982) e perspectiva de Tecnologias Emergentes (CASTRO, 2020).

O presente artigo está organizado de forma a apresentar, primeiramente, estudos de Vygotsky e de pós-vygotskianos sobre o conceito de mediação e as possibilidades de mediação tecnológica em processos educativos como atividade mediadora. Na sequência, discorremos sobre a experiência em Rondônia da implementação do RCRO por meio de um programa de formação realizado $100 \%$ via ERE. Depois, descrevemos o percurso investigativo e problematizamos os resultados que revelam as impressões dos professores envolvidos no processo formativo. Concluímos o texto com nossas considerações finais.

\section{MEDIAÇÃo PEDAGÓGICA EM UMA PERSPECTIVA HISTÓRICO-CULTURAL}

Os pressupostos teórico-metodológicos vinculados à Cultural-Historical Activity Theory (CHAT) têm embasado um grande número de pesquisas, em especial, nas áreas da Psicologia, da Pedologia e da Pedagogia. Sua riqueza conceitual permite o desenvolvimento de teorias e práticas educacionais em variados níveis e contextos, como é possível verificar na coletânea internacional de Selau e Castro (2015).

Lev Semenovich Vygotsky (1896-1934) é o principal expoente dessa perspectiva e o conceito de mediação é um dos mais referenciados em sua obra. Castro (2014) explica que, na perspectiva vygotskiana de formação social da mente (VYGOTSKI, 1931/1995; VYGOTSKY, 1934/1982), toda a relação do ser humano com o mundo, no plano psicológico superior, é mediada. Ao contrário dos outros animais, que se relacionam diretamente com a natureza e entre si (relação com o mundo baseada em instintos e na resolução de problemas imediatos somente em planos de ação concretos), 
os seres humanos, ao desenvolverem ferramentas e signos, alteram a natureza e passam a se relacionar também de forma mediada com o mundo e com os outros seres humanos.

Freitas (2004) salienta que o conceito de mediação se interliga a toda a rede de conceitos de Vygotsky, principalmente, no que se refere à compreensão de um sujeito que, situado histórica e culturalmente, relaciona-se com o mundo de forma mediada. O conceito de mediação proposto por Vygotski (1931/1995), no âmbito educacional, abre caminho para uma compreensão da aprendizagem como um processo não-determinista.

Castro (2014) destaca o esquema proposto por Vygotsky que, apresentado na forma de um triângulo (Figura 01), ajuda a compreender o conceito de mediação em uma perspectiva Histórico-Cultural:

Figura 01. Triângulo de mediação

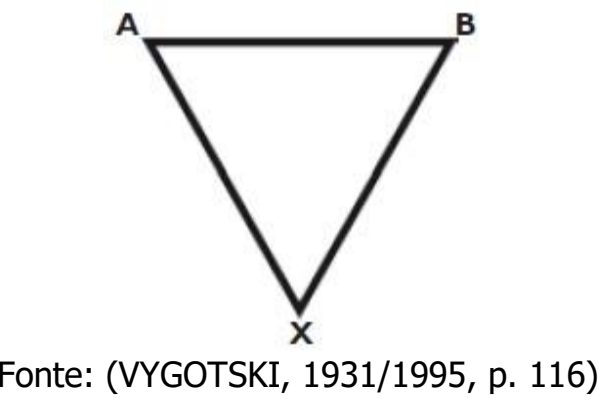

De forma bastante simples, Vygotski (1931/1995) explicava que o processo de relação de A (sujeito) com $B$ (ambiente) é mediado por $X$, onde $X$ é o instrumento (signo ou ferramenta) que propicia a atividade mediadora. Smolka (2000) ressalta que esse conceito é central na teoria de Vygotsky e que, para melhor compreendê-lo, é preciso partir das noções de ferramentas e signos. Vygotsky se apropriou da concepção de ferramentas como meios de trabalho materiais que servem para dominar a natureza, a partir de estudos de Marx e Engels; e definiu os signos como ferramentas psicológicas de mediação entre o ser humano e o mundo, juntando, assim, ambas as noções no conceito geral de artefatos ou adaptações artificiais da atividade mediadora (VYGOTSKI, 1931/1995).

Para Vygotski (1931/1995), a similaridade entre ferramentas materiais e signos baseia-se na função mediadora desempenhada por ambos e, por isso, do ponto de vista psicológico, podem estar incluídos em uma mesma categoria, como ilustra a figura 02:

Figura 02. Atividade mediadora

ATIVIDADE MEDIADORA
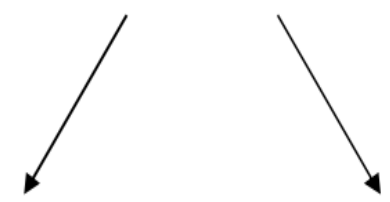

\section{Emprego de Ferramentas Emprego de signos}

Fonte: (VYGOTSKI, 1931/1995, p. 93)

Vygotsky buscou, com essa figura, representar esquematicamente a relação existente entre o emprego de signos e o emprego de ferramentas materiais, pois, para ele: "desde o ponto de vista lógico, tanto um como outro podem considerar-se como conceitos subordinados a um conceito mais geral: a atividade mediadora" (1931/1995, p. 93). Daniels (2003), Freitas (2004) e Castro (2014) 
argumentam que, no campo educacional, pode-se considerar que um livro, uma revista, uma imagem, uma obra de arte, um jogo, um computador [ou uma tecnologia do nosso cotidiano] podem operar como instrumentos mediadores. Obviamente, a efetiva contribuição de qualquer ferramenta ou signo em atividades pedagógicas dependerá do uso que se fará deles, em uma situação educacional específica.

Nos casos do emprego de tecnologias em atividades remotas de formação ou de práticas pedagógicas, típicas do momento vivenciado por educadores de todo o país em função das restrições impostas pela pandemia, tratam-se de atividades mediadoras que se efetivam mediante o uso de ferramentas (computadores, tablets, smartphones, headsets, webcams, microfones, fones etc.) e de signos (linguagem computacional, menus interativos, regras de participação, conceitos de língua inglesa, expressões do "internetês", além da língua falada entre seus participantes).

Contudo, Daniels (2003), Freitas (2004) e Castro (2014) propõem que a noção sobre atividade mediadora também inclua a mediação humana, assim como Vygotsky (1934/1982) se referia acerca da importância do professor no processo de aprendizagem, especificamente, sobre a presença da pessoa mais experiente auxiliando no desenvolvimento da menos experiente - teoria expressa no conceito de Zona de Desenvolvimento Iminente (PRESTES, 2010). Este conceito se mostra deveras relevante se levarmos em consideração a importância dos educadores mais familiarizados com o uso de TE no processo de apropriação dessas habilidades por aqueles que pouco ou nada dominavam desses artefatos antes da pandemia.

A seguir, discutimos sobre o urgente uso de TE como mediadoras em processos educativos remotos - situação demandada pelo contexto de excepcionalidade imposto devido à pandemia global de COVID-19 -, a partir de um olhar Histórico-Cultural.

\section{ATIVIDADES FORMATIVAS E PRÁTICAS PEDAGÓGICAS MEDIADAS POR TECNOLOGIAS EMERGENTES EM TEMPOS DE PANDEMIA}

O conceito de Tecnologias Emergentes vem sendo utilizado na literatura acadêmica recentemente e foi adotado nos estudos vinculados ao Grupo de Pesquisa "HISTCULT - Educação, Psicologia Educacional e Processos Formativos" da Universidade Federal de Rondônia (UNIR), principalmente, por seu caráter atemporal e por superar outras conceituações como Novas Tecnologias (NTIC), Tecnologias da Informação e da Comunicação (TIC) e Tecnologias Digitais Virtuais (TDV) (CASTRO, 2020). Possibilidades pedagógicas propiciadas pelo uso das TE vêm se constituindo em tema de pesquisas no Brasil e no exterior, como as que estamos desenvolvendo no estado de Rondônia no âmbito do grupo de pesquisa acima referido.

$\mathrm{Na}$ literatura acadêmica, é defendido o uso dessas tecnologias como possibilidade de inovação pedagógica em escolas e universidades brasileiras (LUCENA, 2016; OLIVEIRA, CASTRO e FRANÇA, 2020; RODRIGUES, 2018). Além do potencial pedagógico que carregam, deve-se enfatizar que se tratam de artefatos culturais (VYGOTSKI, 1931/1995) que estão fortemente presentes no cotidiano das pessoas. No momento histórico em que este artigo é escrito, entre as TE típicas do século XXI que possibilitam aprendizagem ubíqua e educação híbrida, destacamos o uso das tecnologias móveis em virtude de sua massiva inserção na vida cotidiana. Os dispositivos móveis mudaram a forma como nos relacionamos entre si e com o mundo. Trabalhar pedagogicamente com objetos tão presentes no 
dia-a-dia da escola e da universidade é pensar uma Educação a partir da realidade dos aprendentes e sintonizada com as emergências históricas do século XXI.

Pesquisadoras brasileiras como Eliane Schlemmer e Amarolinda Saccol já investigavam a aprendizagem com mobilidade (m-learning) em 2006. A partir de então, passaram a suscitar possibilidades pedagógicas mediante o uso de dispositivos móveis - divulgadas com maior abrangência em Barbosa, Sacool e Schlemmer (2010). Ao utilizarem o conceito de Tecnologias da Informação Móveis e Sem Fio (TIMS), assim se referiam sobre essas possibilidades:

Aprender com mobilidade não é uma ideia nova - a possibilidade de aprender em qualquer lugar e a qualquer momento sempre foi buscada e potencializada com ferramentas como livros, cadernos e outros instrumentos móveis que existem há muito tempo. O que hoje ocorre é que as TIMS podem contribuir para a Aprendizagem com Mobilidade por disponibilizarem aos sujeitos o acesso rápido a uma grande e diversificada quantidade de informações, viabilizando seu recebimento e envio (quando associadas à internet); além disso, essas tecnologias promovem a comunicação e interação entre pessoas distantes geograficamente e temporalmente, de uma maneira sem precedentes (p. 228).

Antes disso, há quase 20 anos, Hardless, Lundin e Nuldén (2002) já pesquisavam sobre a aprendizagem móvel. Esses autores estudaram profissionais que passam boa parte do tempo viajando ou se deslocando no espaço, de uma reunião para outra e que, com uma significativa carga de trabalho, problemas e desafios emergentes, têm restrições de tempo para realizar cursos de capacitação ou interagir com seus pares para aprender. É nesse sentido que o uso de TIMS é defendido por Barbosa, Saccol e Schlemmer (2010) há dez anos: abrir novas possibilidades de aprendizagem no tempo e no espaço.

Em tempos mais atuais, Lucena (2016), Rodrigues (2018) e Castro (2020) salientam que a segunda década do século XXI está profundamente marcada por outra transformação tecnológica, causada pela frequente utilização das tecnologias móveis conectadas em redes digitais. Segundo Lucena (2016), tablets, notebooks, smartphones e outros dispositivos móveis têm possibilitado uma comunicação desprendida de lugares fixos e que utiliza diferentes linguagens e novos processos sociotécnicos - próprios desse novo ambiente informacional e da cultura da mobilidade. Para esta autora, a comunicação móvel materializa o sentido da expressão tudo ao mesmo tempo agora o tempo todo.

Na concepção de Lucena (2016), atualmente, além da cultura digital e da Cibercultura, vivenciamos a cultura da mobilidade, que se desenvolveu com o constante uso dessas tecnologias móveis, conectadas em redes do tipo Wi-fi, WiMax e peer-to-peer. Dispositivos que cabem na palma da mão e podem ser transportados facilmente para qualquer lugar, criando redes móveis de pessoas e tecnologias nômades localizadas em diferentes espaços geográficos do planeta.

Contudo, mesmo passados quase 20 anos desde os estudos de Hardless, Lundin e Nuldén (2002), a pandemia global de COVID-19 escancarou desigualdades ainda muito marcantes no contexto educacional brasileiro, impossibilitando o acesso a muitas dessas possibilidades por um representativo número de pessoas. Há escolas públicas desenvolvendo experiências exitosas com o uso pedagógico de $T E$, entretanto, em nossa prática cotidiana na área da Educação de mais de 20 anos, mesmo após iniciativas e investimentos públicos e privados, a realidade está longe de ser escolas estruturadas e com docentes e efetivamente capacitados no sentido de incorporar as tecnologias emergentes como mediadores de processos de ensino e de aprendizagem. Nas escolas públicas, são perceptíveis tanto 
a carência de maior e melhor estrutura física e de equipamentos como lacunas na formação dos professores - enquanto já é possível observar um movimento mais avançado de uso de TE em escolas privadas.

Com as medidas de restrições impostas pelo contexto pandêmico, professores que não eram afeitos ao trabalho pedagógico com tecnologias, tiveram que passar a utilizá-las, pois o ERE foi adotado como alternativa por escolas e universidades no sentido de não interromper as atividades educativas. Essas instituições passaram a depender das conexões de internet privadas de professores, pais e estudantes. Mais uma vez, desigualdades brasileiras foram escancaradas: muitas pessoas não dispõem das condições materiais necessárias -computadores, tablets ou mesmo smartphones e conexões de internet adequados - para acompanhar as atividades educacionais propostas.

Quando a conexão de internet possibilita acesso e navegação a seus usuários, diversas ferramentas tecnológicas culturais (típicas das duas primeiras décadas do século XXI) podem ser utilizadas dentro ou fora do denominado Ambiente Virtual de Aprendizagem (AVA). Essas ferramentas podem ser divididas em dois grupos: assíncronas e síncronas. Na comunicação com ferramentas assíncronas, a interação entre os usuários não ocorre em tempo real e o fluxo de informações transcorre de maneira indireta: as mensagens são enviadas e ficam armazenadas, sendo "recebidas" de acordo com a disponibilidade de cada usuário, como, por exemplo, em um fórum. Durante a pandemia, na falta de conexão suficiente de internet por parte de professores, pais e/ou estudantes, a comunicação foi viabilizada pelo envio/recebimento de atividades impressas, o que também pode ser considerado uma tecnologia assíncrona de comunicação móvel. A gravação de vídeo aulas pelos professores, disponibilizada em repositórios online ou em canais educacionais no YouTube, também tem sido utilizada por professores, sendo outro exemplo de comunicação assíncrona móvel.

Já as ferramentas síncronas de comunicação são aquelas utilizadas em tempo real, isto é, nelas a troca de mensagens é instantânea, ocorre simultaneamente e o fluxo de informações é direto. O mais emergente exemplo desse tipo de comunicação são as lives, os webminários, as aulas e as reuniões online utilizando plataformas de comunicação como Google Meet, Zoom, Microsoft Teams, Gotomeeting, Jitsi Meet, Join.me, Zoho Meeting ou os já tradicionais Skype, Google Hangouts, Adobe Connect, Cisco Webex e Web RNP. No YouTube, também é possível ministrar aulas e proferir apresentações em tempo real, configurando-se, nesse caso, também em uma atividade síncrona.

Em todos os casos acima referidos, atividades educacionais são efetivadas mediadas por ferramentas e signos (VYGOTSKI, 1931/1995). Atualmente, muito se fala em ensino remoto, nomenclatura adotada para se referir às atividades educacionais em tempos de pandemia de COVID-19, mas sem uma fonte original sabida. Trata-se, a nosso ver, de atividade online fortemente baseada em comunicação síncrona, massivamente adotada por escolas em todo o Brasil com o objetivo de "não perder o ano letivo". O prejuízo financeiro com o cancelamento das aulas em instituições privadas e o déficit nos estudos de milhões de estudantes brasileiros (de escolas e universidades públicas e privadas) são as principais justificativas para a oferta de "aulas remotas". Desde então, gestores, docentes, estudantes e pais/responsáveis vêm se adaptando a uma realidade "excepcional", mas de forte incidência entre os serviços de Educação e entre as famílias.

De acordo com pesquisa realizada pela Fundação Carlos Chagas (FCC), intitulada "Educação escolar em tempos de pandemia na visão de professoras/es da Educação Básica", no Brasil, 81,9\% dos estudantes da Educação Básica deixaram de frequentar as instituições de ensino. Estima-se cerca de 39 milhões de pessoas. No mundo, esse total soma $64,5 \%$ dos estudantes, o que, em números 
absolutos, representa mais de 1,2 bilhão de pessoas, segundo dados da UNESCO (FCC INFORME 1, 2020). Ainda que, no momento da realização da referida pesquisa, as escolas ainda estivessem em meio a um processo de adaptação, preparando uma rotina escolar "não-presencial remota", para mais de $65 \%$ das docentes entrevistadas, o trabalho pedagógico já havia mudado e aumentado, com destaque para as atividades que envolvem interface e/ou interação digital.

O aumento de atividades relacionadas à tecnologia foi expressivo entre os docentes. Quase oito em cada dez professores afirmaram fazer uso de tecnologias emergentes como ferramentas didáticas (FCC INFORME 1, 2020) durante a pandemia. Muitos intensificaram o uso do e-mail, reinventaram o WhatsApp para usos pedagógicos e tiveram que aprender a participar e/ou liderar videoconferências e a gravar vídeo aulas.

Figura 3. Aumento das atividades docentes em tempo de COVID-19

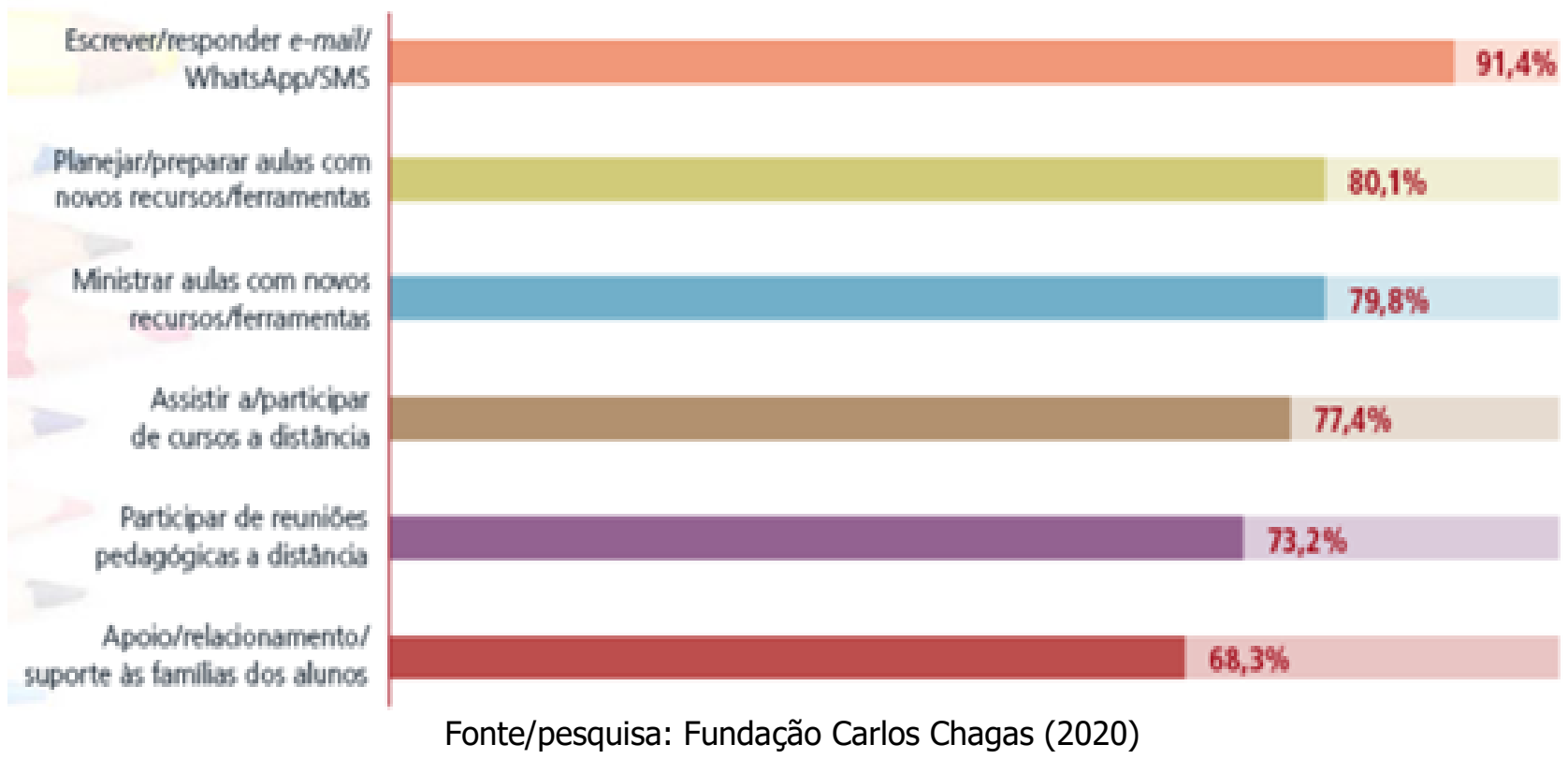

Contudo, longe das TE típicas do século XXI, docentes de localidades mais remotas do país passaram a entregar atividades escolares impressas nas casas dos estudantes. Esses profissionais, nem mesmo em tempos de ERE, tiveram acesso a essas tecnologias e não vivenciaram essa experiência. Nem docentes, nem estudantes. As mudanças impostas pela pandemia destacaram, principalmente: a) o abismo que divide as realidades educacionais entre crianças brasileiras; b) a falta de estrutura tecnológica de muitas escolas públicas; c) o precário acesso à internet a milhões de pessoas; d) o despreparo pedagógico de escolas públicas e privadas em lidarem com atividades online e; e) lacunas na formação de muitos docentes quanto ao uso didático-pedagógico das tecnologias emergentes típicas do século XXI.

Guizo, Marcello e Müller (2020) entendem que o ensino mediado pelas tecnologias exigiu um reajuste nas relações que se estabelecem cotidianamente entre os membros de uma comunidade escolar. Para essas pesquisadoras, em tempos de pandemia, os procedimentos tecnológicos têm provocado alterações e produzido reajustes de relações entre professores e crianças, entre crianças e responsáveis e entre responsáveis e professores - sejam essas tecnologias móveis digitais ou impressas.

Diante desse contexto deflagrado durante a pandemia, e frente ao aligeiramento e ao imediatismo de ações propostas e executadas pelas escolas, atividades de formação também precisaram ser 
repensadas e redimensionadas em todo o país. Professores não afeitos às tecnologias precisaram aprender tecnologia usando tecnologia, em grande medida, por meio de atividades remotas síncronas. Passamos, a seguir, às especificidades das formações remotas realizadas no estado de Rondônia em tempos de COVID-19.

\section{O PROGRAMA De FORMAÇÃO DE PROFESSORES COM FOCO NO REFERENCIAL CURRICULAR DO ESTADO DE RONDÔNIA (RCRO): UMA EXPERIÊNCIA DE ENSINO REMOTO EMERGENCIAL (ERE)}

O Programa de Formação de Professores com foco no Referencial Curricular do Estado de Rondônia (RCRO) é uma estratégia pedagógica para debater, adequar e implementar, com a participação dos professores da Educação Infantil, do Ensino Fundamental e de gestores das redes pública e privada de Rondônia, sobre os pressupostos fundamentais previstos no documento-base do currículo nacional.

O RCRO é fruto de um intenso processo de discussão e elaboração que teve como documento orientador a Base Nacional Comum Curricular (BNCC). A BNCC foi elaborada a partir do embasamento legal que prevê a atualização do referencial curricular nacional que deve direcionar os currículos da Educação Básica (EB) em todo país. Tal previsão legal encontra-se especialmente amparada na Constituição Federal (CF) de 1988, na Lei de Diretrizes e Bases da Educação Nacional (LDB) no 9394, de 1996, e no Plano Nacional da Educação (PNE), Lei no 13.005, de 2014. A Resolução CNE/CP n. ${ }^{\circ}$ 2/2017, que instituiu a BNCC, também orienta sua implantação, determinando sua obrigatoriamente ao longo das etapas e respectivas modalidades no âmbito da EB por meio da adequação dos currículos locais, justificando, assim, a necessidade de elaboração e implementação do RCRO. Desde o início do processo de sua elaboração, em 2015, a BNCC tem sido palco de acirrados debates oriundos da divisão de opiniões conceituais e ideológicas entre renomados educadores e grupos políticos que apresentam divergências sobre as premissas da BNCC.

Os discursos contrários se concentram, em grande parte, na concepção e organização do currículo por campos de experiências na EI e pelas competências gerais e específicas para áreas e etapas no EF; pela redução do tempo de alfabetização; por entenderem que o documento cria uma limitação na autonomia das escolas e dos professores; pelas restrições aos conteúdos citados como "ideologizados"; às questões filosóficas, sociológicas, de gênero e sexo, que não são identificadas no documento base; e, entre outras questões, a BNCC também é vista como forma de controle para subsidiar programas de avaliação nacional.

Em defesa da BNCC, os discursos se concentram na constituição de um avanço significativo da equidade da Educação no Brasil, pois alguns grupos compreendem que o estabelecimento de direitos e objetivos de aprendizagem assegura que todo estudante brasileiro possa desenvolver competências e habilidades de forma equitativa, considerando que a BNCC deve ser ofertada a todas as redes de ensino: públicas e privadas - por meio do seu alinhamento junto aos referenciais curriculares de cada estado e aos currículos municipais e escolares.

Apesar das divergências conceituais e ideológicas, o fato é que a BNCC se constitui num instrumento importante para debater a Educação no país, especialmente, no que diz respeito ao currículo, tão pouco debatido e parcamente aprimorado pelos professores no cotidiano escolar.

Em Rondônia, foram instituídas, em regime de colaboração com a Secretaria de Estado da Educação (SEDUC/RO) e com a União dos Dirigentes Municipais de Educação (UNDIME/RO), equipes de 
profissionais que tiveram, inicialmente, as atribuições de elaborarem o RCRO da Educação Infantil e do Ensino Fundamental e, posteriormente, implementá-lo por meio do programa de formação continuada de professores das redes pública e privada de ensino que atuam com essas etapas de ensino. A formação teve como meta capacitar $70 \%$ desses profissionais, da forma presencial física tradicional.

Para a efetivação da implementação do RCRO, foi definida como estratégia de formação o modelo de cascateamento, em três etapas: 1 . preparação de uma equipe central de formadores; 2 . formação de equipes regionais de formadores, denominados formadores/multiplicadores e; 3. formação de todos os professores do estado que atuam na EI e EF.

Nesse processo formativo, a equipe da UNIDME/RO foi responsável pela formação dos professores de EI e dos Anos Iniciais do EF e a equipe da SEDUC/RO pelos Anos Finais do EF. Contudo, todo o planejamento previsto para ser executado na modalidade presencial física necessitou ser alterado em razão da pandemia, obrigando, entre outras medidas de prevenção, o isolamento social e a consequente suspensão das formações presenciais físicas. Assim, a modalidade das formações precisou ser replanejada para a modalidade remota emergencial.

A UNDIME/RO estruturou o trabalho a partir de duas equipes: a central e a regional. A equipe central dispôs de uma coordenadora geral estadual, duas coordenadoras de etapa (uma para a EI e outra para os Anos Iniciais do EF) e dez formadoras centrais (uma de Língua Portuguesa, uma de Educação Física, uma de Arte, uma de Matemática, uma de Geografia, uma de História, uma de Ciências da Natureza e três da EI). A equipe regional dispôs de professores articuladores e formadores/multiplicadores nos 52 municípios do Estado de Rondônia.

Com o isolamento social, na segunda quinzena do mês de março, foi proposto pela equipe central às equipes regionais a adequação da formação presencial física para a remota. Apesar das dificuldades iniciais, oriundas de uma possível rejeição à formação remota e do pouco conhecimento relacionado ao uso dos artefatos tecnológicos pelos professores, e a qualidade ruim dos serviços de internet ofertados em Rondônia, as equipes regionais aceitaram o desafio de realizar a formação nessa nova perspectiva.

A primeira etapa da formação foi direcionada aos formadores/multiplicadores. Com duração de dois meses, iniciada no início no mês de abril e concluída em junho, foi conduzida pelos formadores centrais. Essa etapa estava assim organizada: 40h de formação ofertadas em seis salas formativas, sendo cinco salas online dos Anos Iniciais do EF (Língua Portuguesa e Arte; Educação Física; Matemática; Ciências Humanas e Ciências da Natureza) e uma sala para a EI.

A etapa formativa seguinte foi conduzida pelos professores articuladores $e$ teve os formadores/multiplicadores como responsáveis pela formação de professores em cada município. Para assegurar essa etapa formativa, a equipe central adotou uma agenda de encontros semanais remotos para a elaboração das pautas, definir as ferramentas e recursos tecnológicos a serem utilizados, auxiliar nos casos de problemas identificados localmente no desenvolvimento das formações e para propiciar trocas de experiências entre as equipes regionais. A definição da carga horária e das salas formativas seguiu a mesma configuração da primeira etapa da formação. A formação dos docentes, ao final, teve duração de quatro meses, com início em julho e término em outubro de 2020 . 
Tratou-se de um processo formativo implementado no decorrer de seis meses via ERE, em função das restrições impostas pela pandemia, o que demandou mudança de modalidade e esforço de muitos profissionais da Educação para se efetivar. Alguns apresentaram dificuldades, outros resistência, constituindo uma mudança de paradigma sentida entre os educadores que vivenciaram a experiência.

A seguir, destacaremos a pesquisa que realizamos junto aos professores articuladores com vistas a identificar limites e possibilidades do uso TE como mediadoras das atividades formativas por esses profissionais.

\section{PERCURSO INVESTIGATIVO}

Tratou-se de uma pesquisa qualitativa (BAUER e GASKELL, 2017), do tipo exploratória (GIL, 2017), relacionada à experiência formativa vivenciada pelo 52 professores articuladores de Rondônia que teve como foco o processo de construção e implementação do RCRO e a excepcionalidade de ter ocorrido integralmente na modalidade denominada ERE, em função da pandemia global de COVID19.

Pesquisas exploratórias, segundo Gil (2017),

têm como objetivo proporcionar maior familiaridade com o problema, com vistas a torná-los mais explícitos ou a construir hipóteses. Pode-se dizer que essas pesquisas têm como objetivo principal o aprimoramento de ideias ou a descoberta de intuições. Seu planejamento é, portanto, bastante flexível, de modo que possibilite a consideração dos mais variados aspectos relativos ao fato estudado (p. 41).

Em nossa pesquisa exploratória, objetivamos identificar aprendizagens, dificuldades vivenciadas, indícios de Trabalho Colaborativo e limites e possibilidades do uso de TE a partir das percepções dos professores articuladores ao longo do processo formativo supracitado. Para tal, aplicamos um questionário misto (GIL, 2017), disponibilizado online via Google Forms a todos os 52 professores articuladores; além da utilização de observação participante (GIL, 2017) por parte de uma integrante do grupo de pesquisa - que vivenciou todo o processo formativo - ao qual este estudo se vincula.

O critério de inclusão de participantes adotado foi estar entre os 52 professores articuladores; e o critério de exclusão foi ser um desses professores, mas não estar disponível, não querer responder ao questionário ou não o responder no prazo em que esteve disponível. Obtivemos $100 \%$ de adesão dos professores articuladores nas respostas ao questionário, o que favorece o grau de confiabilidade da presente pesquisa (BAUER e GASKELL, 2017).

O lócus da investigação foi o estado de Rondônia, especificamente, os espaços ocupados pelos educadores que compõem as redes municipais de ensino do estado. Rondônia é um dos 27 estados do Brasil, localizado na Região Norte. Possui 52 municípios e ocupa uma área de 237.590,547km². Segundo dados do Instituto Brasileiro de Geografia e Estatística (IBGE), possuía 998 escolas de EF, 244 escolas de Ensino Médio (EM) e mais de 15 mil docentes na Educação Básica até 2018 (IBGE, 2019). Até esse mesmo ano, registrou mais de 269 mil matrículas no EF e mais de 59 mil no EM. Segundo o último Censo Educacional (IDEB, 2017), Rondônia apresentou Índice de Desenvolvimento da Educação Básica (IDEB) de 5,7 nos Anos Iniciais e de 4,8 no Anos Finais do EF, ocupando, entre os estados brasileiros, o $8^{\circ}$ e o $5^{\circ}$ lugar, respectivamente. 
Os participantes da pesquisa são profissionais da educação vinculados às Secretarias Municipais de Educação (SEMED) de Rondônia que desenvolvem suas funções nas coordenações pedagógicas dessas secretarias - que foram designados pelos Secretários Municipais de Educação para coordenarem o processo de construção e implementação do RCRO na rede municipal de educação de seu respectivo município.

Dos 52 participantes da pesquisa, os professores articuladores, 75,56\% são do gênero feminino e $24,44 \%$ do masculino. Em relação à formação desses profissionais, 96,96\% possuem habilitação em Pedagogia, 2\% em outras áreas (História, Educação Física e Letras) e 1,04\% não concluíram o Ensino Superior, mas possuem formação técnica em nível de magistério. Seu tempo de trabalho na EB é de até dez anos para $23,08 \%$ deles, até 20 anos para $28,84 \%$ e de mais de 20 anos para $48,08 \%$ dos professores pesquisados.

As respostas dos participantes da pesquisa foram analisadas via análise textual discursiva, como proposto por Moraes (2003), mediante três fases: 1. Unitarização (desmontagem dos depoimentos); 2. Categorização (estabelecimento de relações) e; 3. Construção do metatexto (captando o novo emergente). As unidades de análise foram definidas em função do sentido pertinente aos propósitos da pesquisa, sendo duas categorias definidas a priori e uma que emergiu dos dados. Parte do metatexto, referente a uma das três categorias, será apresentada a seguir.

\section{ANÁLISE DOS DADOS: PERCEPÇÕES DOS PROFESSORES ARTICULADORES ACERCA DO USO DE TECNOLOGIAS EMERGENTES AO LONGO PROCESSO FORMATIVO REMOTO EMERGENCIAL}

Após a Unitarização (MORAES, 2003) dos dados provenientes do questionário aberto respondido pelos 52 professores articuladores do estado de Rondônia sobre o processo de formação visando a implementação do RCRO realizado $100 \%$ via $E R E$, e d observação participante, passamos à fase 2: da Categorização (MORAES, 2003) dos dados por meio do estabelecimento de relações a partir do novo emergente.

Relacionando as respostas ao questionário com as principais impressões oriundas da observação participante de uma pesquisadora, foram estabelecidas três categorias de análise: 1. Aprendizagens e dificuldades de um processo formativo remoto; 2 . Trabalho Colaborativo no processo formativo remoto e; 3. Uso de Tecnologias Emergentes como mediadoras em atividade formativa remota. Para o presente recorte, apresentaremos a síntese do metatexto (MORAES, 2003) relativo à Categoria 3, com dados oriundos das questões $3,6,7$ e 8 do questionário e das observações capturadas do processo formativo.

\subsection{Uso de tecnologias emergentes como mediadoras em atividade formativa remota}

Inicialmente, cabe salientar que o processo formativo ao qual nos referimos ao longo do texto, segundo nossas observações, constituiu-se em uma atividade mediadora efetivamente, como no sentido atribuído por Vygotski (1931/1995), sendo empregados ferramentas e signos ao longo de todo esse processo. As TE, conectadas à internet, artefatos culturais típicos do século XXI, possibilitaram relações mediadas entre os participantes e mediadas entre participantes e conteúdos - constituindo uma atividade mediadora educacional (DANIELS, 2003; FREITAS, 2004, CASTRO, 2014). 
Ao responderem sobre a experiência formativa mediada por ferramentas e signos que possibilitaram relações remotas, quando perguntados sobre "Quais as principais aprendizagens obtidas durante a pandemia no processo formativo?', as tecnologias foram espontaneamente mencionadas por 37 $(71,15 \%)$ dos professores. Esse alto percentual sinaliza a intensidade com que esses artefatos passaram a fazer parte de seus cotidianos laborais (e privados) durante a pandemia e ao longo do processo de formação, indo ao encontro dos achados da pesquisa nacional em larga escala realizada pela Fundação Carlos Chagas (FCC INFORME 1, 2020; FCC INFORME 2, 2020).

O elevado número de professores se referindo ao uso de ferramentas tecnológicas como a principal aprendizagem de um processo formativo, antes mesmo de se referirem às aprendizagens dos conteúdos das formações, indica certo ar de novidade entre eles, pois, se já estivessem habituados ao uso pedagógico desses recursos, provavelmente, não os apontariam de imediato como a principal aprendizagem da formação vivenciada. Fato que nos leva a questionar, consequentemente, a efetividade com que o uso pedagógico das TE vem sendo trabalhado nos cursos de formação inicial e nas formações continuadas das quais participaram, como Castro (2020) questiona em sua pesquisa a partir de análises realizadas sobre os currículos dos cursos de Pedagogia de universidades da Região Norte do Brasil. Também no estado de Rondônia, cabe destacar a contradição verificada em pesquisa realizada com formandos de Pedagogia e com professores da EB de Porto Velho, comunicada por Oliveira, Castro e França (2020), na qual uma turma de formandos se dizia preparada para utilizar pedagogicamente TE em suas futuras práticas pedagógicas, mas que não atribuía essa "sensação de preparação" ao curso de Pedagogia que estavam para concluir no ano de 2018.

Entre as aprendizagens em termos de tecnologias mais mencionadas pelos professores pesquisados ${ }^{34}$, destacamos as que seguem:

A principal foi aprender a lidar com as ferramentas tecnológicas e fazer uso dos ambientes virtuais. (PA4)

Melhor compreensão na utilização das ferramentas tecnológicas. (PA8)

A utilização dos recursos tecnológicos como ferramenta o ensino e aprendizagem. (PA10)

Uso das tecnologias, plataformas salas de classroon. (PA19)

A utilização das TICs e a praticidade do Ensino Remoto. (PA24)

Foram muitas, a princípio aprender a usar as ferramentas tecnológicas, ex: Google Meet, Cisco Webex, sala do Classrrom, foram diversos aprendizados de forma rápida, tivemos que aprender para ensinar. (PA29)

As ferramentas virtuais, como plataformas, salas de aulas virtuais, vídeos. O modo de ensinar e aprender nesse modelo que não é novo, mas de certa forma não era tão usado. (PA33)

Desafio de trabalhar em forma online, aplicativos, [...] tivemos que aprender para ensinar. (PA35)

\footnotetext{
3 Por questões de confidencialidade, os sujeitos da pesquisa não terão seus nomes revelados, sendo identificados pelas iniciais de professor articulador (PA) seguidas do número referente à ordem sequencial cronológica das respostas ao questionário disponibilizado online.

${ }^{4}$ Optamos por manter a grafia original das respostas ao questionário, inclusive, nos casos em que observamos erros de língua portuguesa e/ou de digitação (quando não fosse prejudicada a compreensão da sentença).
} 
Além de poucos depoimentos citando o conteúdo trabalhado durante a formação, as respostas acima pouco (ou nada) aprofundam esse conteúdo. A intensidade do uso das tecnologias durante as formações e a falta dessa intensidade nas formações (inicial e continuada) desses profissionais, possivelmente, trazem as tecnologias para o "centro" do processo formativo e da atuação deles em aulas via ERE nas escolas onde atuam. Trata-se de uma mudança de paradigma que tem marcado nossos professores!

É fundamental destacar, também, que o uso das tecnologias foi apontado como "a principal dificuldade no processo formativo durante a pandemia" por 48 (92,31\%) dos participantes da pesquisa. Dois citaram "o início da formação" e outros dois "a não-presencialidade". Esse resultado salienta, fortemente e mais uma vez, o caráter de "novidade" ao lidarem de forma mais intensa com as TE em atividades educacionais. A falta de formação em termos de uso dessas ferramentas foi referida por metade (26) dos professores articuladores, o que pode ser a origem da resistência de alguns desses profissionais quanto ao uso dessas ferramentas. Se os smartphones já estivessem sendo trabalhados em suas possibilidades pedagógicas, como proposto por Hardless, Lundin e Nuldén (2002), Barbosa, Saccol e Schlemmer (2010) há alguns anos, e por Lucena (2016), Rodrigues (2018) e Castro (2020) mais recentemente, possivelmente, as dificuldades enfrentadas nesse momento não seriam tão fortemente sentidas pelos professores.

Cabe ressaltar, ainda, o contexto precário em termos de conexão de internet no estado de Rondônia, que fica evidente em nossa pesquisa, pois essa dificuldade foi apontada por 29 (55,77\%) professores. Tal dificuldade é acentuada nas cidades no interior do estado caracterizadas como rurais, onde reside parte dos professores em formação. A solução encontrada para minimizar essa problemática por parte das SEMED do estado foi organizar espaços escolares em áreas urbanas das cidades aos professores que tinham dificuldade de acesso à internet e não dispunham de equipamentos (seguindo medidas de segurança em virtude da pandemia de COVID-19).

Em relação às ferramentas síncronas de comunicação, o obstáculo inicial residia no uso de plataformas gratuitas pelos municípios, pois essas não permitiam a participação de mais de 50 professores e o tempo era limitado a 40 minutos de uso. Em regime de colaboração com a SEDUC/RO, esse obstáculo foi superado com a disponibilização de acesso à plataforma Cisco. A SEDUC criou e-mails para todos os municípios com a finalidade de viabilizar a formação mediante contrato - que permitiu a participação de até 1000 pessoas e tempo ilimitado de uso. Isso possibilitou, para cada etapa da formação, a média de 15 encontros síncronos e dez atividades assíncronas em cada município.

Ao serem perguntados sobre "o que identificavam como mudança ou inovação na Educação com as formações mediadas por tecnologias (não presenciais)", a mudança de modalidade (da tradicional física para a remota) foi o apontamento mais representativo em suas respostas, sendo as tecnologias mencionadas por todos os professores em suas respostas, com destaque para as que seguem:

[...] Aprendi que a formação remota foi e está sendo muito produtiva levando em consideração as contribuições dos cursistas. (PA01)

A principal mudança é o fato de que as reuniões se tornaram todas remotas e que a tecnologia é uma ferramenta poderosa que auxilia em muito a construção do aprendizado. (PA02)

Um novo olhar voltado para a educação, novas perspectivas. (PA04)

Nova visão da educação utilizando as mídias. (PA05) 
Incentivo a utilização das ferramentas digitais como inovação da prática pedagógica. (PA08)

[...] a grande inovação na educação com as formações mediadas por tecnologia é que todos se reinventaram e construíram uma novos modelos de ensinar com a oportunidade de compartilhar saberes tornando -se sujeitos pró-ativos, buscando estratégias inovadoras que jamais usariam se fosse de forma presencial (PA09)

A educaçõa dispoe de muitas inovações tecnológicas para serem usardas nesse periodo de pandemia, porem temos o papel de adequar a estas mudaças, obtende novas aprendizagens. (PA14)

Creio que o uso das plataformas para palestras, roda de conversa, debates e outros irá fazer parte do nosso contexto educacional, a organização e o investimento nos espaços tecnológicos também é uma inovação. (PA28)

O uso de TE no processo formativo, realizado $100 \%$ em formato online, foi positivamente avaliado pelos professores articuladores. A sensação de satisfação por eles expressa em suas respostas pode ser sintetizada nas palavras de PA20, PA22 e PA23:

a principal mudança foi compreender que é possível fazer formação de qualidade pela plataforma. Que é possível aprender participando online. Que é possível ter uma formação prazerosa, mesmo que seja cada um na sua casa. (PA20)

Possibilidade de um ensino Híbrido, também em formações continuadas. Penso que as plataformas serão nossas aliadas por muito tempo. A pandemia nos mostrou que podemos agilizar o tempo e a distância com reuniões virtuais. Ter a possibilidade dos dois: presencial e não presencial será um ganho! (PA22)

O rompimento de tabus/barreiras tecnológicas é o maior aprendizado neste momento, aprender a lidar com o novo criar, recriar e utilizar essa ferramenta para facilitar, viabilizar, VEICULAR informação, possibilitar interação virtual/online. Há anos essa ferramenta está disponível e sempre a resistência muito grande em utiliza-la, com a modalidade não presencial virtual abriu-se um leque de opções adormecidos pelo comodismo, medo, de experimentar, desmistificando ideia de, "difícil"o uso tecnológico nas escolas e salas de aulas. (PA23)

Levando em consideração que a maioria dos professores articuladores participava das reuniões de formação mediados por seus smartphones, e tendo em vista que muitos não dispunham de notebook ou tablet, os depoimentos otimistas acima corroboram com as possibilidades levantadas por Hardless, Lundin e Nuldén (2002) no início deste século, por Barbosa, Saccol e Schlemmer (2010) há exatos dez anos, e por Lucena (2016), Rodrigues (2018) e Castro (2020) pouco antes da pandemia, sobre possibilidades do uso de tecnologias móveis em processos educativos. Os docentes pesquisados experienciaram suas benesses e passaram a vislumbrar suas possibilidades pedagógicas mediante 0 processo formativo, o que pode refletir em suas práticas em um contexto pós-pandemia.

O acúmulo de trabalho dos docentes da EB, mesmo que não sendo enfatizado pelos participantes da pesquisa, foi mencionado por PA14 e deve ser registrado, pois essa formação remota ocorreu concomitantemente à adaptação desses profissionais ao ERE e a todo um investimento em estudos, produção de novos materiais - em formato digital ou impresso - que o caráter excepcional da pandemia exigiu dos professores: 
de trabalho maior do que antes, pois está sempre disponível para tirar dúvida dos alunos e das familias. (PA14)

Mais uma vez, enfatizamos a importância de uma maior aproximação dos professores com as possibilidades pedagógicas das $\mathrm{TE}$, essencialmente, com as tecnologias móveis, principais responsáveis pela comunicação entre escola e comunidade atendida em tempos de pandemia. Contudo, antes de tudo, é necessário prover formação e propiciar condições materiais aos docentes para que o uso pedagógico dessas tecnologias seja incorporado em práticas educacionais e que esse tipo de recurso didático inovador esteja a serviço da equidade e não da exclusão.

\section{CONSIDERAÇÕES FINAIS}

A presente pesquisa objetivou investigar, a partir das percepções dos denominados professores articuladores, que participaram de um processo formativo direcionado à implementação do novo Referencial Curricular no estado de Rondônia, limites e possibilidades a partir de um novo formato: remoto e totalmente online. Abordar a temática das TE aplicadas à Educação ainda é um tema atual e se torna ainda mais relevante em tempos de pandemia e de ensino remoto, o que destaca a importância da pesquisa realizada no contexto histórico complexo vivenciado no ano de 2020.

Os dados, provenientes da aplicação de um questionário (GIL, 2017) online e de observação participante (GIL, 2017), foram analisados à luz da análise textual discursiva (MORAES, 2003) e produziram os seguintes achados: i. em uma perspectiva vygotskiana, as tecnologias utilizadas atuaram tanto na condição de ferramentas como de signos na atividade mediadora formação remota; ii. as aprendizagens mais relevantes durante as formações, segundo os professores articuladores, foram aquelas relativas ao uso das tecnologias, mais mencionadas até do que os próprios conteúdos trabalhados ao longo dos encontros; iii. as principais dificuldades foram a conexão de internet precária nos municípios e a falta de conhecimento sobre o uso das tecnologias por uma quantidade representativa de professores; iv. todos os professores respondentes se mostraram conscientes da importância do domínio de tecnologias em suas práticas como educadores e otimistas com relação à utilização pedagógica das mesmas em um futuro pós-pandemia.

Entendemos que as atividades mediadoras (VYGOTSKI 1931/1995) empreendidas em formato online remoto, no contexto específico pesquisado no estado de Rondônia, mesmo que realizadas de forma aligeirada devido às excepcionalidades impostas por uma pandemia global, propiciaram uma espécie de "formação continuada excepcional" para o trabalho pedagógico com TE aos professores, que passaram a gravar vídeo aulas, a ministrar aulas ao vivo e a produzir novos materiais em formato digital (e impresso), individual e coletivamente.

Em meio a um contexto global de pandemia e a uma série de desafios impostos à sociedade contemporânea, esta pesquisa apresenta apenas algumas das primeiras contribuições no sentido de entender o que estamos fazendo em termos de processo formativo e de prática pedagógica na Educação Básica em tempos de pandemia. Outras frentes de estudo ainda são necessárias no sentido de estabelecermos estratégias para não sobrecarregar professores, não penalizar estudantes e não prejudicar famílias e trabalhadores já afetados por uma pandemia em um país ainda marcado por desigualdades. 


\section{REFERÊNCIAS}

BARBOSA, Jorge; SACCOL, Amarolinda Z.; SCHLEMMER, Eliane. M-Learning E U-Learning: Novas Perspectivas Da Aprendizagem Móvel E Ubíqua. Pearson Brasil: São Paulo, 2010.

BAUER, Martin. W.; GASKELL, George. (Orgs.). Pesquisa Qualitativa com Texto, Imagem e Som: um manual prático. 6. ed. Petrópolis: Vozes, 2017.

CASTRO, Rafael F. de. A expressão escrita de acadêmicas de um curso de pedagogia a distância: uma intervenção Histórico-Cultural. 2014. 238f. Tese (Doutorado) - Programa de Pós-Graduação em Educação. Universidade Federal de Pelotas, Pelotas, 2014.

CASTRO, Rafael F. de. Tecnologias Emergentes e Formação de Professores: o que as grades curriculares de cursos de Pedagogia sinalizam? In: Múltiplos Olhares sobre a Formação de Professores no Brasil. (Orgs.) SILVA, Marijâne S.; PEDROSA, Neide B.; ISOBE, Rogéria M. R. Porto Velho: EDUFRO, 2020.

DANIELS, Harry. Vygotsky e a Pedagogia. São Paulo: Edições Loyola, 2003.

FCC INFORME 1. Fundação Carlos Chagas. Educação escolar em tempos de pandemia na visão de professoras/es da Educação Básica - Informe no 1 . Disponível em: <https://www.fcc.org.br/fcc/wp-content/uploads/2020/06/educacao-pandemia-a4_16-06_final.pdf

>. Acesso em: 24 de agosto de 2020.

FCC INFORME 2. Fundação Carlos Chagas. Educação escolar em tempos de pandemia na visão de professoras/es da Educação Básica - Informe no 2 . Disponível em: <https://www.fcc.org.br/fcc/wp-content/uploads/2020/06/educacao-pandemia-a4_16-06_final.pdf >. Acesso em: 08 de novembro de 2020.

FREITAS, M. T. A. O pensamento de Vygotsky nas reuniões da ANPEd (1998-2003). Educação e Pesquisa, São Paulo, v. 30, n. 1, p. 109-138, 2004.

GIL, Antônio C. Como elaborar projetos de pesquisa. 6. ed. São Paulo: Atlas, 2017.

GUIZZO, Bianca S.; MARCELLO, Fabiana A.; MÜLLER, Fernanda. A reinvenção do cotidiano em tempos de pandemia. Educ. Pesqui., São Paulo, v. 46, e238077, 2020.

HARDLESS, C.; LUNDIN, J.; NULDÉN, U. Mobile Competence Development for Nomads. Anais do... Proceeding of the Hawaii International Conference on System Sciences, 34, Hawaii, 2002.

IBGE CIDADES. Instituto Brasileiro de Geografia e Estatística. IBGE CIDADES. 2019. Disponível em: <https://cidades.ibge.gov.br/brasil/ro>. Acesso em: 11 set. 2020.

IDEB. Anos iniciais do ensino fundamental / Anos finais do ensino fundamental (Rede pública): Ministério da Educação, Instituto Nacional de Estudos e Pesquisas Educacionais (INEP) - Censo Educacional 2017. Disponível em: <http://ideb.inep.gov.br/resultado>. Acesso em: 12 set. 2020.

LUCENA, Simone. Culturas digitais e tecnologias móveis na educação. Educar em Revista, Curitiba, n. 59, p. 277-290, jan./mar. 2016.

MORAES, Roque. Uma tempestade de luz: a compreensão possibilitada pela análise textual discursiva. Ciência e Educação, Bauru, v. 9, n. 2, p. 191-211, 2003. 
OLIVEIRA, Delziana; CASTRO, Rafael F. de; FRANÇA, Rosângela F. C. Percepções de professoras sobre o uso pedagógico de Tecnologias Emergentes: uma investigação em Porto Velho/RO. Revista Educar Mais, v. 4, n. 2, 2020.

PRESTES, Zoia Ribeiro. Quando não é quase a mesma coisa: análise de traduções de Lev Semionovitch Vigotski no Brasil. 2010. 232f. Tese (Doutorado) - Programa de Pós-Graduação em Educação. Universidade Federal de Brasília, Brasília, Brasil.

RODRIGUES, Jadiael S. As tecnologias móveis como possibilidade de inovação no ensino de História: uma análise da aplicação do Projeto HMOBILE em uma escola pública no município de Candeias do Jamari/RO. 2018. 112. Dissertação (Mestrado) - Programa de PósGraduação em Educação. Universidade Federal de Rondônia, Porto Velho, Brasil

SELAU, Bento; CASTRO, Rafael F. de. Cultural-historical approach: educational research in different contexts (Orgs.) Bento Selau da Silva Jr., Rafael Fonseca de Castro. Porto Alegre: EDIPUCRS, 2015.

SMOLKA, Ana Luiza B. O (im)próprio e o (im)pertinente na apropriação das práticas sociais. Cadernos Cedes, n. 50, v. 20, 2000.

VYGOTSKI, L. S. Obras Escogidas Tomo III (Historia del Desarrollo de las Funciones Psíquicas Superiores). Madri: Visor, 1931/1995.

VYGOTSKY, L. S. Obras Escogidas II (Pensamiento Y Lenguaje). Moscú: Editorial Pedagógica, $1934 / 1982$. 